\title{
Strategy for Sustainable and Green Chromatographic Separation Science: Innovation, Technology and Application
}

\author{
Mohammad Sharif Khan ${ }^{1, *}$, Jannatul Azmir ${ }^{1}$, Ademario Iris da Silva Junior ${ }^{2}$, Yong Foo Wong ${ }^{3}$, \\ Mamun Mollah ${ }^{4}$, Mohammad Khairul Alam ${ }^{5}$, Jalal T. Althakafy ${ }^{6}$ and Md. Zaidul Islam Sarker
}

${ }^{1}$ Thayer School of Engineering, Dartmouth College, 14 Engineering Drive, Hanover, NH, 03755, United States, ${ }^{2}$ Insti-
tuto Federal do Rio de Janeiro, Rua Senador Furtado 121, Rio de Janeiro, CEP 24220031, Brazil. ${ }^{3}$ School of Chemi-
cal Sciences, Universiti Sains Malaysia, 11800 Penang, Malaysia. ${ }^{4}$ School of Chemistry, Monash University, Welling-
ton Rd, ClaytonVIC3800, Australia. ${ }^{5}$ Institute of Nutrition and Food Science, University of Dhaka, Dhaka-1000,
Bangladesh. ${ }^{6}$ Department of Chemistry, Faculty of Applied Sciences, Umm Al-Qura University, Makkah, Saudi Arabia.
${ }^{7}$ Faculty of Pharmacy, International Islamic University Malaysia, 25200, Kuantan, Pahang, Malaysia

\begin{abstract}
Green separation science involves extraction, pre-concentration and chromatographic analysis aiming at minimizing environmental impact by reducing energy and reagent usage and reducing or eliminating waste generation. However, the enrichment of trace analytes and/or the analysis of complex matrices most frequently require several steps before analysis, such as extraction, pre-concentration, clean up and preparative chromatography. Thus, alternative and greener separation techniques and solvents are replacing classical methods to diminish the carbon footprint and increase sustainability. Moreover, many innovations are also emerging to curtail the environmental impact of samples analysis; such as micro or nano analytical platforms, sensor-based systems and direct injection to high-resolution mass spectrometry. The current review provides an updated account of the green and sustainable separation science techniques. The current innovations on greener separations and their application in different fields of study are discussed.
\end{abstract}

Keywords: Sustainable chemistry, green separation science, alternative sample preparation, micro-analytical techniques, multidimensional chromatography, green chromatography.

\section{INTRODUCTION}

Green chemistry has become a major trend, as evidenced by a recent editorial in "Green Chemistry" journal [1]. The editor stated a simple but important question to consider before branding a new method, process or reaction as "Green": Is the new chemistry greener than what has been done before? This question has modified the checklist in selecting a "green chemistry" definition, as this concern is no longer limited only to the domain of chemistry. A Web of Science ${ }^{\circledR}$ search of "green chemistry" in the last five years has resulted in 10,926 total articles (Fig. 1). In (a), the steady increase in the number of articles reflects the rise in importance of this field, whereas in (b) the sources of funding grants demonstrate the universal concern about green chemical science. In (c), the applications of this concept are so widespread and so comprehensive that it has been applied in many different fields starting from chemistry to condensed matter physics.

Green separation science is a term that combines preparative and analytical chromatography. Different goals are re-

* Address correspondence to this author at the Thayer School of Engineering, Dartmouth College, 14 Engineering Drive, Hanover, NH, 03755, United States; Tel. 9032316556; E-mail: sharifsks@yahoo.com quired to make sure that the process can be assigned as green separation science $[2,3]$. Some organizations and institutes have defined green chemistry in several research articles [4-6]. The main criteria are (1) the reduction of the use of chemical reagents, (2) the minimization of energy consumption, (3) the sustainability of the management of analytical waste, and (4) the appropriate safety of the personnel [7-9].

The most common measurement of the outcome of a separation method is the recovery rate of a particular analyte from its matrix. This recovery rate is a function of solubility as well as the extractability of the separation solvents [7-9]. In recent years, many different types of solvents for separation have evolved, with a particular emphasis on the recovery of analytes. However, the concern about the environmental effect of these organic solvents and the rise of green chemistry methods sparked the development of a green separation science subgroup that tries to ally the yield in recovery rate with solvents that entail more sustainable and greener properties.

This current contribution has discussed the green separation science, its importance, innovation and application over the last few years. The last part of this review provides a perspective on this field and the future that is projected in the separation science. 


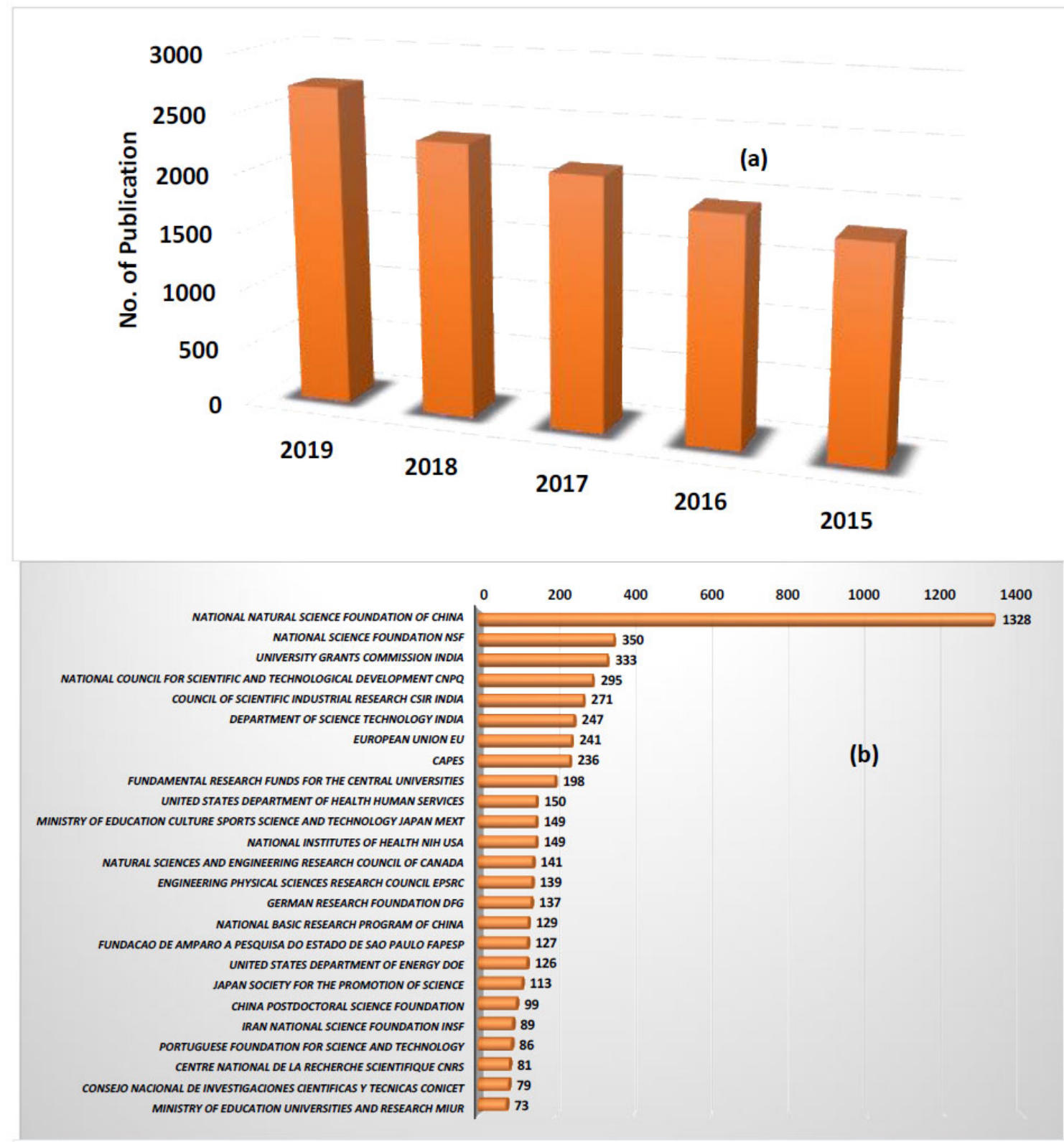

(c)

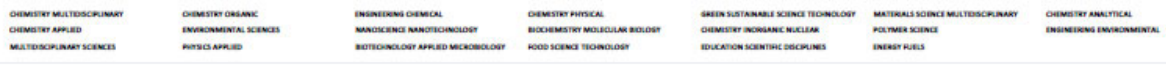

Fig. (1). Figures for 10,926 entries in Web of Science ${ }^{\circledR}$ derived from the "green chemistry" keyword: (a) the number of entries during the last 5 years; (b) the funding sources for these studies and (c) the fields of study for this keyword in which the area size reflects the number of publications. (A higher resolution / colour version of this figure is available in the electronic copy of the article). 


\section{GREEN CHEMISTRY IN PREPARATIVE CHRO- MATOGRAPHY}

Most of the efforts on greener separation are in the preparative field of chromatography. The preparative chromatography, as the name suggests, is the initial stage for the analysis where the targeted analyses are separated from the sample matrices. The global statistics for the use of organic solvents in preparative chromatography are not available. However, a quick search in the literature shows that these solvents are few and not quite diverse. Even though the use of organic solvents is more controlled in the research environment when compared to industrial applications. However, the use of organic solvent always puts a lot of challenges on the environment [10]. A number of innovative and newer technologies have been introduced, and some have shown a promising reduction in the use of solvents for preparative chromatography (Fig .2). Supercritical fluids, ionic liquids and micro extraction are a few of those and will be discussed in the following sections for their application on solvent reduction.

\subsection{Supercritical Fluid}

Supercritical fluids (SFs) are a category that can be used in green separation techniques as alternative solvents. SF is a fluid phase of any substance at a temperature and pressure above its critical point where the distinction between liquid and gas phase does not exist and the unique properties of this fluid phase are intermediate between typical liquids and gases $[11,12]$. The fundamental interest in SFs arises because of the environmental reasons and their unique SFs poses lower densities and viscosities, and higher diffusivities in comparison with the liquids. The properties of SFs can be easily tuned by changing the temperature and pressure. The tuning properties of a SF are an added benefit that helps the achievement of the recovery required for a particular analysis.

Carbon dioxide has been mostly used so far because of the convenient critical temperature and pressure, low price, noninflammability, chemical stability and nontoxicity. The utility of a supercritical fluid in sample preparation methods has already been well established [2]. Its application on chromatography as a single method or hyphenated with other analytical methods is also getting more attention [13]. One recent example of the recent application of supercritical fluids is the enhancement of chiral chromatographic separations by eight-fold in plate counts [14].

A very recent example of SF application is the combination of SF extraction and SF chromatography online for the extraction and analysis of hydrophilic compounds. This method has been optimized to use a minimal amount of samples required for the splitting function for analysis. Moreover, this process improved separation efficiency [15]. A SF method was reported to remove the lipid layer from the artery of the patient and analyze it using a QTOF-MS. This method could separate the lipid layer within seven minutes using a Zero organic solvent [16]. There are many examples of SF extraction that exist in the literature for the extraction of plant metabolites $[12,17,18]$, which did not use any organic solvent and can be considered as green separation approaches.

\subsection{Ionic Liquids}

Ionic liquids are another prominent example of green separation, including extraction and chromatography [19]. The application of ionic liquids has been well demonstrated and established $[19,20]$ in separation science since their discovery in 1914 [21] because of their unique solvating properties related to their polarity and ionic character, negligible vapour pressure and high thermal stability. Ionic liquids are organic salts with melting points equal to below $100{ }^{\circ} \mathrm{C}$.

Many ionic liquids are almost ideal constituents of stationary phases in gas chromatography (GC) due to their tunable selectivity through structural modifications, high viscosity, and high thermal stability as already thoroughly described [22]. These types of stationary phases provide unique separation for both polar and non-polar compounds in complex mixtures since ionic liquids have dual nature behavior $[23,24]$. Talebi and co-authors described the use of ionic liquids as stationary phases in $\mathrm{GC}$ with examples in their recently published book chapter [22]. The use of a new generation of inert ionic liquid GC columns has improved the original ionic liquid stationary phase performance. An article published in 2018 investigated the inert ionic liquid column comprising phosphonium or imidazolium cationic species for the separation of methyl esters of fatty acids [25]. This column set was also compared with the conventional ionic liquid columns (IL111, IL111i) and comprised of low column bleeding, which makes it more suitable for multidimensional GC in analyzing methyl esters of fatty acids.

Ionic liquids have been incorporated into high-performance liquid chromatography (HPLC) separations, although not only as immobilized new HPLC stationary phases but also as additives to mobile phases. Many studies are using ionic liquids as additives in HPLC [26-28], which have been broadly discussed by Ali and co-authors [29]. Wang et al., studied the separation of eleven 4,4-diamino stilbene-2,2-disulfonic acid-based fluorescent whitening agents with different numbers of sulfonic acid groups using ionic liquid as a mobile phase additives in HPLC [30]. They also investigated the effects of ionic liquid concentration, $\mathrm{pH}$ and composition of the mobile phase on this separation and discerned the better ionic liquid.

Due to their structural tunability, ionic liquids can be applied in several sample extraction methods such as liquidliquid extraction (LLE), single-drop microextraction (SD$\mathrm{ME}$ ), dispersive liquid-liquid micro-extraction (DLLME), and solid-phase microextraction (SPME) [31]. Though LLE is the most widely used extraction technique, the use of toxic organic solvents limits its use. First, LLE was modified by replacing those organic solvents by 1-butyl-3-methylimidazolium hexafluorophosphate as a novel ionic liquid extraction solvent for nineteen different compounds, including acids, alcohols and bases as well as benzene and its deriva- 


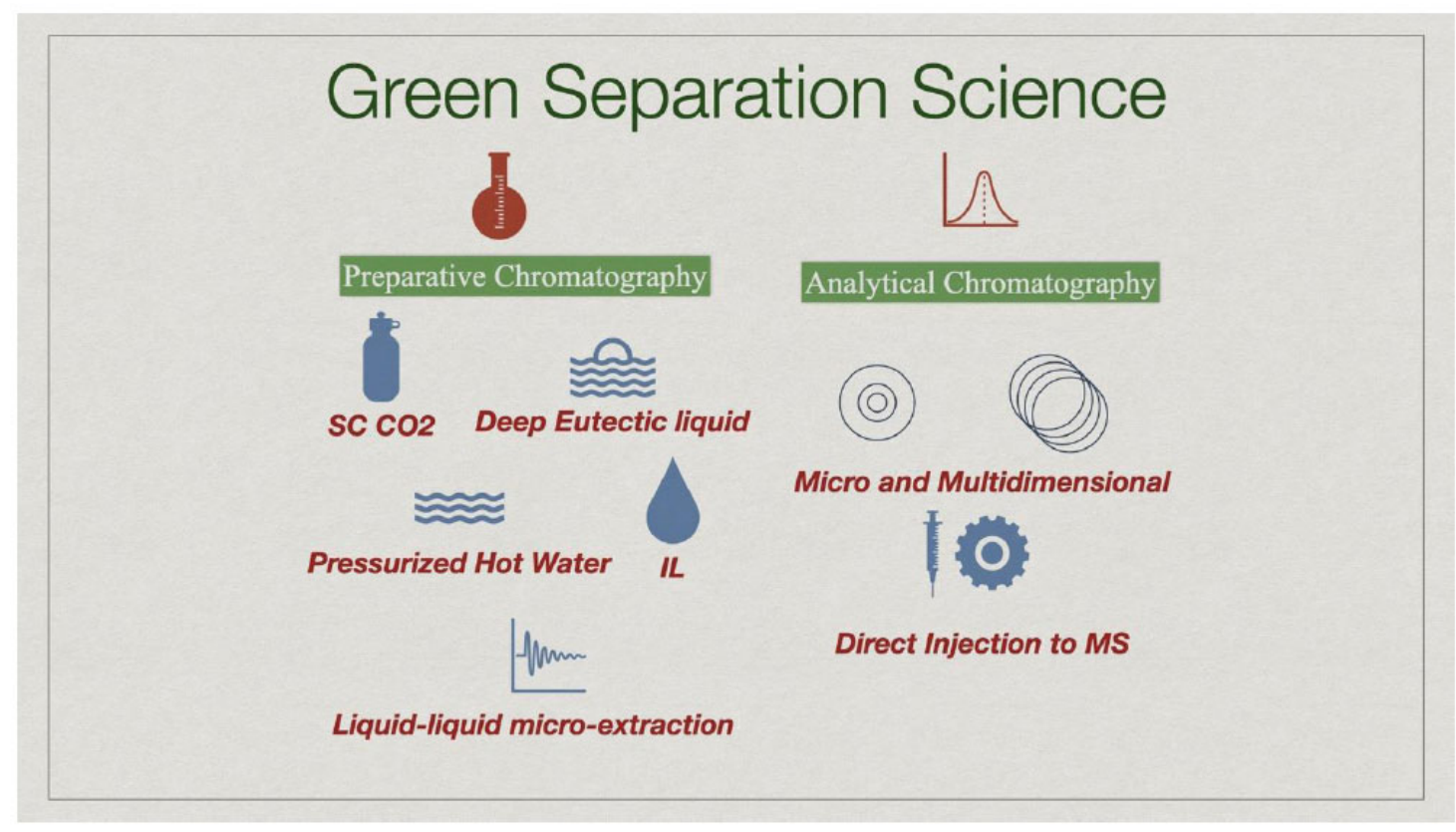

Fig. (2). The analytical techniques that are in line with the greener and sustainable separation techniques. (A higher resolution / colour version of this figure is available in the electronic copy of the article).

tives [32]. DLLME was first introduced in 2006 and since then, it has attracted enormous attention in separation science. DLLME on ionic liquids has been applied to determine organic compounds and metals in a variety of matrices such as in water, food and biological samples; as described in the review article by Rykowska et al. [33]. Another review by Trujillo-Rodríguez et al., summarized most of the studies in this field conducted from 2008 to 2013 [34].

\subsection{Deep Eutectic Solvents}

Deep Eutectic solvents (DES) are classified as a type of ionic liquids. Though ionic liquids are one of the most widely studied areas in separation science in the past decade, their high price and toxicity hampered their industrial emergence. To overcome these drawbacks of ionic liquids, DESs have emerged as a new generation of solvents that can employ the ionic liquid concept more rationally. DESs are a mixture of two or three components associated with each other by hydrogen bond to form a eutectic mixture [35]. In most cases, a quaternary ammonium salt is associated with a metal salt or hydrogen bond donor, which are cheap and safe components used to synthesize the DES mixture. The resulting mixture possesses a lower melting point than each individual component due to charge delocalization through hydrogen bonding; the halide anion and hydrogen moiety are responsible for the decreasing melting point [36]. This mixture is also characterized by a lower freezing point than that of each individual component, which is below $150{ }^{\circ} \mathrm{C}$ for all reported DESs.

In the first study of DESs, Abbott et al., (2001) heated a range of quaternary ammonium salts with $\mathrm{ZnCl}_{2}$ and ob- served a lower freezing point and a lower melting point of the resulting mixture than each ammonium salt or $\mathrm{ZnCl}_{2}$ alone [36]. Their study was extended and many liquids have been used to form eutectic mixtures of ammonium salts and hydrogen donors [37]. The applications of DESs for extracting and separating target compounds are well documented and can be found in the review articles by Smith et al., and Zhang et al. [35, 38]. The use of DESs in the field of extracting and separating target compounds is also well established and well documented in the literature [39, 40].

One of the most important uses of DES is in biodiesel purification, where the DES can remove the residual $\mathrm{KOH}$ catalyst and purify the crude biodiesel [41]. It can also be applied for the removal or decrease of aromatic hydrocarbons from chemical products [42] and the separation/storage of greenhouse gases; $\mathrm{CO}_{2}$ and $\mathrm{CH}_{4}$ [43]. It also has usage in bioactive compounds extraction and separation from living organisms, tissues or cells; which are widely known for providing beneficial effects on human health [44-46]. For example, headspace DES microextraction prepared by mixing choline chloride with ethylene glycol at different ratios extracted terpenoids from Chamaecyparis obtusa leaves [47]. The terpenoids swiftly extracted by this method showed various anti-disease properties like antimicrobial, antitumor and antimalarial activities. As a green extractive solvent, Yilmaz et al., applied choline chloride DES in an ultrasound-assisted extraction of iron from various animals' liver samples in 2015 [48]. In 2015, DES was used to prepare DES-based silica as a stationary phase sorbent by Tang et al., [49]. By the same token, DES was also used as a mobile phase additive to improve separation in HPLC [50]. 


\subsection{Pressurized Hot Water Extraction}

Pressurized hot water extraction (PHWE) is an extraction technique based on water at a temperature range higher than the boiling point $\left(100^{\circ} \mathrm{C}\right)$ and lower than its critical point $\left(374{ }^{\circ} \mathrm{C}\right)$. While extracting, moderate pressure needed to be employed, such as $0.1 \mathrm{MPa}$ for $100^{\circ} \mathrm{C}$ and $22.1 \mathrm{MPa}$ for $374{ }^{\circ} \mathrm{C}$ [51]. Nowadays, PHWE has become a popular green extraction technique for the extraction of various types of compounds from different types of environmental, food and plant materials. It has also been used for the extraction and removal of organic compounds from foodstuff and soils to ensure food safety and environmental monitoring [52]. PHWE is an alternative to organic solvent extraction which uses pressurized water to extract compounds at high temperature and controlled pressure. The main concept of this method is to change the polarity of water, similar to those of alcohols by using certain temperatures and pressures. Thus it can dissolve a wider range of medium and low polarity compounds [53-56]. There are some major advantages of PHWE since it reduces the consumption of organic solvents in extraction, water is available everywhere and is non-toxic, easily disposable and recyclable with minimum environmental difficulties. It is a low-cost method that is efficient in extracting less-polar organic compounds from a variety of matrices [52, 57, 58].

The first study to report PHWE was conducted in 1994 by the pioneer of this field, Hawthorne and co-workers. They applied the pressurized water at elevated temperatures to extract polar and non-polar compounds from soil samples [59]. This method is being widely used to extract bioactive compounds from plant materials. For example, Liau and coauthor applied PHWE to extract glycosides of flavonoids from defatted Camellia oleifera seeds [60] and studied the efficiency of experimental factors (temperature, time and pressure) on the extraction. The optimized process employed $140{ }^{\circ} \mathrm{C}, 600 \mathrm{psi}$ and $10 \mathrm{~min}$ of extraction time. Another study reported the extraction of bioactive compounds from Stevia rebaudiana Bertoni leaves, which are the natural sources of diterpenic glycosides and various bioactive compounds [61]. They have studied the effect of various temperatures, extraction times and number of cycles at constant pressure, and observed that temperature plays a crucial role in PHWE extraction of bioactive compounds. They concluded that PHWE is a useful method to recover polar and nonpolar antioxidants and steviol glycosides. A study from 2018 reported the preparation of ready to drink iced tea from sage (Salvia officinalis L.) and linden (Tilia cordata) by the combination of PHWE and spray-drying [62]. In that study, the phenolics of sage and linden were extracted by PHWE first, and then the extracts were spray-dried by the addition of maltodextrin. Finally, sucrose and citric acid were added to the spray-dried product to obtain ready to drink iced tea.

\subsection{Liquid-phase Microextraction Techniques}

Liquid-phase microextraction (LPME), one of the miniaturized liquid-liquid extraction (or solvent extraction) techniques that are considered as an environment-friendly mi- croextraction approach, minimizes the use of organic solvents and/or highly toxic chemicals [63]. In general, LPME involves extracting and preconcentrating target analytes into a few microliters of extraction solvent [64]. Some notable advantages of LPME include easy operation, low solvent and sample consumption, being environmental-friendly (compared to liquid-liquid extraction) and provide high enrichment factor (high sample volume-to-extractant/acceptor volume ratios) for targeted analytes [65].

LPME can be classified into the exposed solvent and protected solvent microextraction modes. The two most common protected microextraction solvent modes are hollow fibre liquid-phase microextraction (HF-LPME) and electromembrane microextraction (EME), that use the microvolume of the extraction solvent stored within a porous membrane, e.g. a polypropylene hollow fiber. Key advantages of these modes are the protection of extraction solvents against chemical interferences and contaminants within the samples [66]. The applications of polypropylene hollow fibre liquidphase microextraction (HF-LPME) in many analytical-based studies are well-reviewed [67-69]. However, it is important to take note of the long extraction time required for HFLPME, which is one of the major drawbacks of this passive diffusion-based technique [70]. EME has emerged as an interesting alternative to address such limitation by combining concentration gradient with electrically driving force to facilitate the diffusion of the analytes into the acceptor phase. In EME, the applied electrical potential difference promotes the charged analytes to electrokinetically migrate from the donor or sample solution through a supported liquid membrane into the acceptor solution, which results in shorter extraction time [71].

Recently, Armin Fashi et al., reported the development of an EME technique for the fast extraction and preconcentration of melamine in dairy products. EME combined with HPLC-UV detection technique has been applied for the determination of melamine in the range of 7-8000 $\mathrm{ng} \mathrm{mL}^{-1}$ (LOD of $2.0-5.8 \mathrm{ng} \mathrm{mL}^{-1}$ ), with enrichment factor in the range of 82-192. In this approach, the extraction time was 15 min, which is much shorter when compared with the HFLPME technique $(60 \mathrm{~min})$ that provided a detection limit of $0.003 \mathrm{mg} \mathrm{kg}^{-1}[72,73]$. For exposed solvent microextraction modes, SDME and DLLME are among the popular techniques preferred by analytical chemists. SDME was first introduced by Liu and Dasgupta in 1996, and utilizes liquid droplet as a sampling interface to extract chemical substances from the air [74]. The technique then underwent different developments (e.g. direct immersion-SDME, headspace-SDME, continuous-flow microextraction (CFME) and others) to cater to various applications $[74,75]$. Versatility and simplicity of operations are the key advantages of SDME that generally requires only a standard analytic syringe.

Among all the LPME-based techniques, DLLME is regarded as the most recently introduced microextraction technique that was first developed by Assadi and co-workers in 2006 [76]. In DLLME, an appropriate proportion of high-- 
density extraction (e.g. chlorobenzene) solvent and water-miscible disperser solvent (e.g. $\mathrm{MeOH})$ is rapidly injected into a sample solution using an analytical syringe. Analytes or solutes of interest within the sample solution are dissolved in the micro-droplets of extraction solvent and are then concentrated in the immiscible phase [77]. A comprehensive discussion on SDME and DLLME principles and analysis has been made in a few systematic reviews; therefore, we do not intend to reiterate that information in this review [77-79]. Worth mentioning is the recent development in DLLME by using magnetic ionic liquid (MIL) as an extractant phase that has been successfully demonstrated by Fiorentini and co-workers. They used trihexyl (tetradecyl) phosphonium tetrachloroferrate (III) as the MIL with acetonitrile as a dispersant for the selective extraction of As (III) species that have been chelated by acidified ammonium diethyldithiophosphate. The MIL phase was then separated using a magnet, and the aliquot was directly injected into the graphite furnace of electrothermal atomic absorption spectrometry for the measurement of As in honey. A sensitivity enhancement factor of 110 and limit of detection of $12 \mathrm{ng}$ $\mathrm{L}^{-1}$ were achieved using the above-stated approach [80]. Fig. (2) summarizes the techniques presented in section 2 of this text.

\section{GREEN CHEMISTRY IN ANALYTICAL CHROMA- TOGRAPHY}

Chromatography methods are justifiably considered green, i.e., they use increasingly lower quantities of samples and solvents and have an excellent performance in sensitivity, precision and accuracy. They have been steadily improved since the birth of the instrumental version of the technique [81].

At the same time, chromatographic methods are exceptionally well-positioned concerning the twelve principles of green analytical chemistry [82] since they have (i) low and diminishing waste generation [83] (ii) medium energy consumption [84], (iii) use small quantities of the sample [85], (iv) are increasingly resorted to automation/miniaturization [86], (v) are readily coupled to other analytical techniques [87], and (vi) are also multianalyte methods by definition. Although (vii) derivatization should be avoided, it is still widely used in both gas (to increase volatility and thermal stability) and liquid (to increase detectability) chromatographic method [88]. (viii) The toxicity of derivatization reagents [89] can reduce the safety for the operator, which is normally high in chromatographic analyses without them. (ix) However, replacement and elimination of toxic reagents and methods have been under development and stimulated by increasingly tight legislation. The worst-case scenario for a green principle of analytical chemistry in chromatography is the use of $(\mathrm{x})$ in situ measurements since sampling for external analysis is mandatory [90] and even gas chromatography - normally faster than liquid chromatography - cannot give impromptu results. Nevertheless, not only field instruments have been available [91] but also chromatographic methods can use automatic sampling and run in parallel, if the whole operation can wait and (xi) the direct injection of matrices into the analytical system is possible, which is not so common but can happen, e.g., in the analysis of gaseous off-products by gas chromatography [92]. (xii) The use of renewable sources for mobile phase is the subject of many publications in liquid chromatography [93] and the wide usage of $\mathrm{He}$ in gas chromatography has not only been disputed but also the other available options $-\mathrm{N}_{2}$ and $\mathrm{H}_{2}$ - have also been under study and experimentation [94].

\subsection{Micro-HPLC, Narrower Columns in GC and Multi- -Dimensional Techniques}

The early and ulterior developments of chromatography theory always indicate that the reduction in particle size and column diameter would bring the increase in separation power and speed [95]. However, only when technology developments allowed the production of homogeneous particles and columns as well as pumps with steady flows that could overcome the necessary ultrahigh pressures, these small dimensions became feasible to every lab [96]. Since these evolutions elicit faster analysis, less mobile phase consumption, the injection of smaller amounts, and the increase of the signal to noise relationship, they make liquid chromatography a greener methodology as well.

The concept of micro-HPLC as the miniaturization of HPLC systems was conceived a long time ago [97], even though what was considered micro-HPLC in 1985 is today "normal" HPLC. Indeed, column dimensions are still diminishing to the size of microchips that integrate injection and detector ports that help reduce void volumes [98]. These latter developments allowed the sampling of minimum volumes and have been thoroughly used in biological, biomedical and biochemistry applications [99]. They also reduced the use of solvents to very small volumes. The columns are laser blasted canals into the chips whose walls can be chemically coated just as GC capillary columns. These column diameters are in the micrometer domain, which allows more than reasonable chemical interaction and exceptional resolution achievements [85].

\subsection{Multi-Dimensional Techniques}

Multidimensional chromatography is a recent trend in the chromatography field as it provides a massive improvement in peak capacity (the number of theoretical peaks that could be positioned at the separation space). This process involves sample injection into at least two dimensions of separation in tandem to have an enhanced analysis. Peaks that are subjected to only one dimension of separation might not be completely resolved, which is often known as the overlapping issue of single-dimensional analysis [100]. In comprehensive two-dimensional scenarios, for example, samples are sliced in a very narrow sampling time to a very short second dimension to have another independent separation. Numerous improvements and applications have been demonstrated using this comprehensive two-dimensional method as proof of the utility of a complete separation of samples [101].

Non-comprehensive two-dimensional methods can also be used to enhance the analysis of just a section of the chro- 
matogram that is sampled to another column. In this latter case, the second column can have larger lengths, since just one slice is introduced to another chromatographic run that can last any time [102].

The multidimensional techniques are considered sustainable, and green when compared to single-dimensional analyses not only because of the improved peak capacities but also because of other well-defined benefits. Multidimensional techniques often offer (a) shorter run times, (b) shorter columns, (c) extended columns lifetime because of reducing exposure to high temperature, (d) less column bleeding, (e) less sample requirement for each analysis, which reduces the organic solvent usage per sample, (f) less use of carrier gas, electricity and other resources per sample, and $(\mathrm{g})$ reduced maintenance of the detectors. There is a very well elaborated review article on this topic covering the theory, instrumentation and application of the multidimensional techniques [103].

\subsection{Direct-Injection Mass Spectrometry (DIMS)}

Currently, there are good arguments about the utility of the separation techniques in the analyses before the mass spectral analysis. In the last few years, huge progress has been made in mass spectrometry and its sample introduction processes, which can make the previous sample separation obsolete for some types of samples analyses. These alternatives of sample preparation methods have been studied for the high-throughput and cost-effective analyses.

One of the very well-studied methods without any sample preparation is called DIMS or Direct Injection to Mass Spectrometry. This method has already proved to be highly sensitive and selective and an attractive alternative for the existing methods. DIMS is stable, and it is not prone to drift in the mass spectral ratio, which is important for compound identification. Several derivatives of this method have been discussed in the literature, such as Atmospheric pressure chemical ionization (APCI), Selected-ion flow-tube mass spectrometry (SIFT-MS) and Proton-transfer-reaction mass spectrometry (PTR-MS). The main idea of these techniques is to produce an ion product of the samples before it gets into the mass spectrometry for detection. Metabolomic studies, food analysis, VOCs, and agricultural studies have been described in the literature [104].

From a green separation perspective, it is advantageous to use direct analysis as it removes chromatography section in the sample analysis pathway, which would reduce the use of the chemical for sample preparation, resources for the chromatography analysis and would be more energy saving. Additionally, direct injection to mass spectra often requires a very small amount of sample that is beneficial for some type of sample analysis. However, because of the strong matrix effect, it is not often recommended for complex sample analysis. Nevertheless, recent developments in chemometrics and statistical tools have helped in solving matrix problems [105, 106].

The direct injection to mass spectra has been a key player in the food sickens. A recent example shows the injection of mammalian serum for a clinical lipidomics study to quantify the cholesterol ester and free cholesterol coupled to electrospray ionization high-resolution mass spectrometry (ESI-HRMS) without any sample preparation. Compared to a typical sample preparation approach, this process is greener concerning a) the solvent use, b) resource use, c) cost and many more [107]. The direct injection techniques which eliminate the preconcentration step reduce the required sample volume for a challenging sample collection, e.g. marine organic substances confined in ice [108]. This process also eliminates the potential to introduce additional contamination during the pre-concentration process [109]. Numerous other examples are reported in the literature with an intention to reduce the solvent used. However, there are few limiting factors on the applicantion of this method, such as a) very complex matrix, b) increased data processing, and c) poor sensitivity of the method.

\section{FUTURE PERSPECTIVES}

The sample preparation will probably continue to resort to automation and preparative chromatography since it can increase analysis speed and reduce costs. The use of greener solvents or water in high temperature and pressure will also probably evolve, provided that they reduce the cost and increase speed as well.

Miniaturization and automation have been in steady development and application almost from the beginning of chromatography. Both gas and liquid methods will probably continue the shrinkage of injectors, columns and detectors as well as the lower consumption of mobile phase, sample and standards, which will contribute to the ever increasingly greener applications, the greener renovations of old methods and the development of green new ones for wider usage.

Multidimensional methods may continue their evolution mainly in the "omics" domain, where they may be the only ones that can deal with the sheer number of substances that come from very complex matrices and are required to be fully determined. At the same time, they can be able to maintain their green characteristics due to the equipment shrinkage mentioned above.

The higher throughput of analysis, the whole lot of chemical information generated and the number of substances analyzed in each sample increasingly demand the use of chemometrics to make sense of the sheer volume of data. Besides, chemometrics will continue to allow the coupling of some instrumental techniques that produced spectral information which did not suit well in mixtures before the advancement of multivariate data treatment. However, now these techniques can provide insightful information since they can be chemometrically resolved. Without chemometrics, many direct sampling applications would not be feasible.

However, the gap of the chemical higher education towards greener chemistry must be tackled to secure a widespread usage of greener methods and the creation of greener solutions all around the world. Chemometrician also needs a better formation in Linear Algebra conceive many other ap- 
plications for if they have at least a basic understanding of the fundamentals of chemometrics.

Some of the issues that will probably continue to bother chemists around the world are the increasing cost of instrumentation and their non-sustainability. Every time a type of instrumentation is turned obsolete, their destination is uncertain, their spare parts will disappear from the market, and even if they still can be useful, the technical assistance will diminish, and repair will be increasingly costly. It is not uncommon to see still useful instruments with accessories that still work after just being dumped to be substituted for up-to-date instruments in laboratories that can afford it. This is a topic that it is not yet green and should be dealt with.

\section{CONCLUSION}

The environmental concern that leads to greener and sustainable separation science is steadily evolving. As a consequence, a number of attempts have been made throughout the last couple of years to reduce the use of hazardous chemicals for separation science. The methods and techniques that showed promising results are still under development, and newer techniques are emerging in these fields. All these innovations are taking shape to meet the sustainability criteria by environmental agencies as well as economic consideration of consumers and industry.

\section{CONSENT FOR PUBLICATION}

Not applicable.

\section{FUNDING}

MSK and JA acknowledge Dartmouth College for support. YFW acknowledges the support from the USM Short Term Research Grant; 203.PKIMIA. 6315191.

\section{CONFLICT OF INTEREST}

The authors have no conflicts of interest, financial or otherwise.

\section{ACKNOWLEDGEMENTS}

Declared none.

\section{REFERENCES}

[1] Abbott, A.P.; Capper, G.; Davies, D.L.; Munro, H.L.; Rasheed R.K.; Tambyrajah, V. Preparation of novel, moisture-stable, Lewis-acidic ionic liquids containing quaternary ammonium salts with functional side chains. Chem. Commun. (Camb.), 2001, (19), 2010-2011.

[http://dx.doi.org/10.1039/b106357j] [PMID: 12240264]

[2] Abbott, A.P.; Capper, G.; Davies, D.L.; Rasheed, R.K.; Tambyrajah, V. Novel solvent properties of choline chloride/urea mixtures. Chem. Commun. (Camb.), 2003, (1), 70-71. [http://dx.doi.org/10.1039/b210714g] [PMID: 12610970]

[3] Alam, M.K.; Rana, Z.H.; Islam, S.N. Comparison of the proximate composition, total carotenoids and total polyphenol content of nine orange-fleshed sweet potato varieties grown in Bangladesh. Foods, 2016, 5(3), 64. [http://dx.doi.org/10.3390/foods5030064] [PMID: 28231159]
[4] Alam, M.K.; Rana, Z.H.; Islam, S.N.; Akhtaruzzaman, M. Comparative assessment of nutritional composition, polyphenol profile, antidiabetic and antioxidative properties of selected edible wild plant species of Bangladesh. Food Chem., 2020, 320, 126646.

[http://dx.doi.org/10.1016/j.foodchem.2020.126646] [PMID: 32229398]

[5] Alaşalvar, H.; Çam, M. Process for production of ready to drink iced teas from sage (Salvia officinalis L.) and linden (Tilia cordata): pressurized hot water extraction and spray drying. Food Sci. Biotechnol., 2018, 28(3), 779-785.

[http://dx.doi.org/10.1007/s10068-018-0538-3]

[PMID: 31093435

[6] Ali, I.; Suhail, M.; Sanagi, M.M.; Aboul-Enein, H.Y. Ionic liquids in HPLC and CE: a hope for future. Crit. Rev. Anal. Chem., 2017, 47(4), 332-339.

[http://dx.doi.org/10.1080/10408347.2017.1294047] [PMID: 28266865]

[7] Anastas, P.; Eghbali, N. Green chemistry: principles and practice. Chem. Soc. Rev., 2010, 39(1), 301-312.

[http://dx.doi.org/10.1039/B918763B] [PMID: 20023854]

[8] Anastas, P.; Han, B.; Leitner, W.; Poliakoff, M. "Happy silver anniversary": Green Chemistry at 25. Green Chem., 2016, 18(1), 12-13. [http://dx.doi.org/10.1039/C5GC90067K]

[9] Andersson, T.; Pihtsalmi, T.; Hartonen, K.; Hyötyläinen, T.; Riekkola, M-L. Effect of extraction vessel geometry and flow homogeneity on recoveries of polycyclic aromatic hydrocarbons in pressurised hot water extraction. Anal. Bioanal. Chem., 2003, 376(7), 1081-1088.

[http://dx.doi.org/10.1007/s00216-003-2078-8] [PMID: 12856099]

[10] Azmir, J.; Zaidul, I.; Rahman, M.; Sharif, K.; Sahena, F.; Jahurul, M.; Mohamed, A. Optimization of oil yield of Phaleria macrocarpa seed using response surface methodology and its fatty acids constituents. Ind. Crops Prod., 2014, 52, 405-412.

[http://dx.doi.org/10.1016/j.indcrop.2013.11.009]

[11] Azmir, J.; Zaidul, I.; Sharif, K.; Uddin, M.; Jahurul, M.; Jinap, S. Supercritical carbon dioxide extraction of highly unsaturated oil from Phaleria macrocarpa seed. Food Res. Int., 2014, 65, 394-400. [http://dx.doi.org/10.1016/j.foodres.2014.06.049]

[12] Azmir, J.; Zaidul, I.S.M.; Rahman, M.M.; Sharif, K.M.; Mohamed, A.; Sahena, F. Techniques for extraction of bioactive compounds from plant materials: A review. J. Food Eng., 2013, $117(4), 426-436$.

[http://dx.doi.org/10.1016/j.jfoodeng.2013.01.014]

[13] Bello-López, M.Á.; Ramos-Payán, M.; Ocaña-González, J.A.; Fernández-Torres, R.; Callejón-Mochón, M. Analytical Applications of Hollow Fiber Liquid Phase Microextraction (HF-LPME): A Review. Anal. Lett., 2012, 45(8), 804-830.

[http://dx.doi.org/10.1080/00032719.2012.655676]

[14] Berthod, A.; Ruiz-Ángel, M.J.; Carda-Broch, S. Recent advances on ionic liquid uses in separation techniques. J. Chromatogr. A, 2018, 1559, 2-16.

[http://dx.doi.org/10.1016/j.chroma.2017.09.044] [PMID: 28958758]

[15] Biasioli, F.; Yeretzian, C.; Märk, T.D.; Dewulf, J.; Van Langenhove, H. Direct-injection mass spectrometry adds the time dimension to (B)VOC analysis. Trends Analyt. Chem., 2011, 30(7), 1003-1017. [http://dx.doi.org/10.1016/j.trac.2011.04.005]

[16] Bruner, F. 1985, The Science of Chromatography: Lectures AJP Martin Honorary Symposium,

[17] Bursać Kovačević, D.; Barba, F.J.; Granato, D.; Galanakis, C.M.; Herceg, Z.; Dragović-Uzelac, V.; Putnik, P. Pressurized hot water extraction (PHWE) for the green recovery of bioactive compounds and steviol glycosides from Stevia rebaudiana Bertoni leaves. Food Chem., 2018, 254, 150-157.

[http://dx.doi.org/10.1016/j.foodchem.2018.01.192] [PMID: 29548436]

[18] Buse, J.; Robinson, J.L.; Shyne, R.; Chi, Q.; Affleck, D.; Duce, D.; Seiden-Long, I. Rising above helium: A hydrogen carrier gas chromatography flame ionization detection (GC-FID) method for the simultaneous quantification of toxic alcohols and ethylene glycol in human plasma specimens. Clin. Biochem., 2019, 73, 
98-104.

[http://dx.doi.org/10.1016/j.clinbiochem.2019.08.007] [PMID: 31425671]

[19] Chatzimichail, S.; Casey, D.; Salehi-Reyhani, A. Zero electrica power pump for portable high-performance liquid chromatography. Analyst (Lond.), 2019, 144(21), 6207-6213.

[http://dx.doi.org/10.1039/C9AN01302D] [PMID: 31573005]

[20] Chokkareddy, R.; Niranjan, T.; Redhi, G.G. Ionic liquid based electrochemical sensors and their applications.Green Sustainable Process for Chemical and Environmental Engineering and Science; Elsevier, 2020, pp. 367-387.

[http://dx.doi.org/10.1016/B978-0-12-817386-2.00013-5]

[21] de Sousa Brandão, I.L.; Mannaerts, C.M.; de Sousa Brandão, I.W.; Queiroz, J.C.B.; Verhoef, W.; Fonseca Saraiva, A.C.; Dantas Filho, H.A. Conjunctive use of in situ gas sampling and chromatography with geospatial analysis to estimate greenhouse gas emissions of a large Amazonian hydroelectric reservoir. Sci. Total Environ., 2019, 650(Pt 1), 394-407.

[http://dx.doi.org/10.1016/j.scitotenv.2018.08.403] [PMID: 30199684]

[22] El-Shaheny, R.; El-Maghrabey, M.; Belal, F. Micellar Liquid Chromatography from Green Analysis Perspective. Open Chem., 2015, 13 [http://dx.doi.org/10.1515/chem-2015-0101]

[23] Farajzadeh, M.; Sorouraddin, S. Liquid phase microextraction of pesticides: A review on current methods. Mikrochim. Acta, 2014, 181, 829-851. [http://dx.doi.org/10.1007/s00604-013-1157-6]

[24] Fashi, A.; Yaftian, M.R.; Zamani, A. Determination of melamine in dairy products using electromembrane-LPME followed by HPLC. Food Chem., 2015, 188, 92-98.

[http://dx.doi.org/10.1016/j.foodchem.2015.04.132] [PMID: 26041169]

[25] Fekete, S.; Grand-Guillaume Perrenoud, A.; Guillarme, D. Evolution and Current Trends in Liquid and Supercritical Fluid Chromatography. Curr. Chromatogr., 2014, 1, 15-40.

[http://dx.doi.org/10.2174/22132406114019990002]

[26] Fiorentini, E.F.; Canizo, B.V.; Wuilloud, R.G. Determination of As in honey samples by magnetic ionic liquid-based dispersive liquid-liquid microextraction and electrothermal atomic absorption spectrometry. Talanta, 2019, 198, 146-153.

[http://dx.doi.org/10.1016/j.talanta.2019.01.091] [PMID 30876542]

[27] Gałuszka, A.; Migaszewski, Z.; Namieśnik, J. The 12 principles of green analytical chemistry and the SIGNIFICANCE mnemonic of green analytical practices. Trends Analyt. Chem., 2013, 50, 78-84. [http://dx.doi.org/10.1016/j.trac.2013.04.010]

[28] Gao, L.; Jönsson, J.Å. Determination of Melamine in Fresh Milk with Hollow Fiber Liquid Phase Microextraction Based on Ion-Pair Mechanism Combined with High Performance Liquid Chromatography. Anal. Lett., 2012, 45(16), 2310-2323.

[http://dx.doi.org/10.1080/00032719.2012.688084]

[29] Gerhardt, R.F.; Peretzki, A.J.; Piendl, S.K.; Belder, D. Seamless Combination of High-Pressure Chip-HPLC and Droplet Microfluidics on an Integrated Microfluidic Glass Chip. Anal. Chem., 2017, 89(23), 13030-13037.

[http://dx.doi.org/10.1021/acs.analchem.7b04331] [PMID: 29096060]

[30] Gil-Ramirez, A.; Al-Hamimi, S.; Rosmark, O.; Hallgren, O.; Larsson-Callerfelt, A-K.; Rodríguez-Meizoso, I. Efficient methodology for the extraction and analysis of lipids from porcine pulmonary artery by supercritical fluid chromatography coupled to mass spectrometry. J. Chromatogr. A, 2019, 1592, 173-182.

[http://dx.doi.org/10.1016/j.chroma.2019.01.064]

[PMID: 30709622]

[31] González-Ruiz, V.; León, A.G.; Olives, A.I.; Martín, M.A.; Menéndez, J.C. Eco-friendly liquid chromatographic separations based on the use of cyclodextrins as mobile phase additives. Green Chem., 2011, 13(1), 115-126. [http://dx.doi.org/10.1039/C0GC00456A]

[32] Hassas-Roudsari, M.; Chang, P.R.; Pegg, R.B.; Tyler, R.T. Antioxidant capacity of bioactives extracted from canola meal by subcritical water, ethanolic and hot water extraction. Food Chem., 2009, 114(2), 717-726.

[http://dx.doi.org/10.1016/j.foodchem.2008.09.097]
[33] Hawthorne, S.B.; Yang, Y.; Miller, D.J. Extraction of organic pollutants from environmental solids with sub-and supercritical water. Anal. Chem., 1994, 66(18), 2912-2920.

[http://dx.doi.org/10.1021/ac00090a019]

[34] Höring, M.; Ejsing, C.S.; Hermansson, M.; Liebisch, G. Quantification of Cholesterol and Cholesteryl Ester by Direct Flow Injection High-Resolution Fourier Transform Mass Spectrometry Utilizing Species-Specific Response Factors. Anal. Chem., 2019, 91(5), 3459-3466.

[http://dx.doi.org/10.1021/acs.analchem.8b05013]

[PMID: 30707563

[35] Houbart, V.; Fillet, M. Advances in Low Volume Sample Analysis Using Microfluidic Separation Techniques Advances in Microfluidics-New Applications in Biology, Energy, and Materials Sciences, 2016, 1

[http://dx.doi.org/10.5772/64952]

[36] Hu, B.; Chen, B.; He, M.; Nan, K.; Xu, Y.; Xu, C. Chapter Four Separation methods applied to arsenic speciation.Comprehensive Analytical Chemistry; Duarte, A.C.; Reis, V., Eds.; Elsevier, 2019, Vol. 85, pp. 89-144.

[37] Huddleston, J.G.; Willauer, H.D.; Swatloski, R.P.; Visser, A.E.; Rogers, R.D. Room temperature ionic liquids as novel media for 'clean' liquid-liquid extraction. Chem. Commun., 1998, (16), 1765-1766.

[http://dx.doi.org/10.1039/A803999B]

[38] Ishtiaq, M.; al-Rashida, M.; Alharthy, R.D.; Hameed, A. Ionic liquid-based colloidal nanoparticles: applications in organic synthesis.Metal Nanoparticles for Drug Delivery and Diagnostic Applications; Elsevier, 2020, pp. 279-299.

[http://dx.doi.org/10.1016/B978-0-12-816960-5.00015-X]

[39] Jain, A.; Verma, K.K. Recent advances in applications of single-drop microextraction: a review. Anal. Chim. Acta, 2011, 706(1), 37-65.

[http://dx.doi.org/10.1016/j.aca.2011.08.022] [PMID: 21995911]

[40] James, A.T.; Martin, A.J. Gas-liquid chromatography; a technique for the analysis and identification of volatile materials. Br. Med. Bull., 1954, 10(3), 170-176.

[http://dx.doi.org/10.1093/oxfordjournals.bmb.a069416] [PMID: 13199288]

[41] Jeannot, M.A.; Przyjazny, A.; Kokosa, J.M. Single drop microextraction--development, applications and future trends. J. Chromatogr. A, 2010, 1217(16), 2326-2336.

[http://dx.doi.org/10.1016/j.chroma.2009.10.089] [PMID: 19932482]

[42] Jessop, P. Editorial: Evidence of a significant advance in green chemistry. Green Chem., 2020, 22(1), 13-15.

[http://dx.doi.org/10.1039/C9GC90119A]

[43] Kaljurand, M.; Koel, M. Recent advancements on greening analytical separation. Crit. Rev. Anal. Chem., 2011, 41(1), 2-20.

[http://dx.doi.org/10.1080/10408347.2011.539420]

[44] Kim, W-J.; Kim, J.; Veriansyah, B.; Kim, J-D.; Lee, Y-W.; Oh, SG.; Tjandrawinata, R.R. Extraction of bioactive components from Centella asiatica using subcritical water. J. Supercrit. Fluids, 2009, 48(3), 211-216.

[http://dx.doi.org/10.1016/j.supflu.2008.11.007]

[45] King, A.C.F.; Giorio, C.; Wolff, E.; Thomas, E.; Roverso, M.; Schwikowski, M.; Tapparo, A.; Bogialli, S.; Kalberer, M. Direct Injection Liquid Chromatography High-Resolution Mass Spectrometry for Determination of Primary and Secondary Terrestrial and Marine Biomarkers in Ice Cores. Anal. Chem., 2019, 91(8), 5051-5057.

[http://dx.doi.org/10.1021/acs.analchem.8b05224] [PMID: 30893554]

[46] Kocúrová, L.; Balogh, I.; Šandrejová, J.; Andruch, V. Recent Advances in Dispersive Liquid-Liquid Microextraction Using Organic Solvents Lighter than Water. A Review. Microchem. J., 2011, 102, 11-17.

[http://dx.doi.org/10.1016/j.microc.2011.12.002]

[47] Koel, M. , 2012, pp. Energy Savings in Analytical Chemistry.Handbook of Green Analytical Chemistry; 289-319. [http://dx.doi.org/10.1002/9781119940722.ch15]

[48] Kronholm, J.; Hartonen, K.; Riekkola, M-L. Analytical extractions with water at elevated temperatures and pressures. Trends 
Analyt. Chem., 2007, 26(5), 396-412.

[http://dx.doi.org/10.1016/j.trac.2007.03.004]

[49] Lambropoulou, D.A.; Albanis, T.A. Application of hollow fiber liquid phase microextraction for the determination of insecticides in water. J. Chromatogr. A, 2005, 1072(1), 55-61.

[http://dx.doi.org/10.1016/j.chroma.2004.11.076] [PMID: 15881459]

[50] Lee, J.; Lee, H.K.; Rasmussen, K.E.; Pedersen-Bjergaard, S. Environmental and bioanalytical applications of hollow fiber membrane liquid-phase microextraction: a review. Anal. Chim. Acta, 2008, 624(2), 253-268

[http://dx.doi.org/10.1016/j.aca.2008.06.050] [PMID: 18706332]

[51] Li, X.; Row, K.H. Development of deep eutectic solvents applied in extraction and separation. J. Sep. Sci., 2016, 39(18), 3505-3520. [http://dx.doi.org/10.1002/jssc.201600633] [PMID: 27503573]

[52] Liang, J.; Frazier, J.; Benefield, V.; Chong, N.S.; Zhang, M. Forensic Fiber Analysis by Thermal Desorption/Pyrolysis-Direct Analysis in Real Time-Mass Spectrometry. Anal. Chem., 2020, 92(2), 1925-1933.

[http://dx.doi.org/10.1021/acs.analchem.9b04167]

[PMID: 31846295]

[53] Liau, B-C.; Ponnusamy, V.K.; Lee, M-R.; Jong, T-T.; Chen, J-H. Development of pressurized hot water extraction for five flavonoid glycosides from defatted Camellia oleifera seeds (byproducts). Ind. Crops Prod., 2017, 95, 296-304. [http://dx.doi.org/10.1016/j.indcrop.2016.10.034]

[54] Lin, S-L.; Lin, T-Y.; Fuh, M-R. Microfluidic chip-based liquid chromatography coupled to mass spectrometry for determination of small molecules in bioanalytical applications: an update. Electrophoresis, 2014, 35(9), 1275-1284.

[http://dx.doi.org/10.1002/elps.201300415] [PMID: 24165927]

[55] Liu, H.; Dasgupta, P.K. Analytical chemistry in a drop. Solvent extraction in a microdrop. Anal. Chem., 1996, 68(11), 1817-1821. [http://dx.doi.org/10.1021/ac960145h] [PMID: 21619093]

[56] MacNair, J.E.; Lewis, K.C.; Jorgenson, J.W. Ultrahigh-pressure reversed-phase liquid chromatography in packed capillary columns. Anal. Chem., 1997, 69(6), 983-989.

[http://dx.doi.org/10.1021/ac961094r] [PMID: 9075400]

[57] Marriott, P.J.; Haglund, P.; Ong, R.C.; Schmarr, H-G.; Bieri, S. A review of environmental toxicant analysis by using multidimensional gas chromatography and comprehensive GC. Clin. Chim. Acta, 2003, 328(1-2), 1-19.

[http://dx.doi.org/10.1016/S0009-8981(02)00382-0] [PMID: 12559594]

[58] Martín-Calero, A.; Pino, V.; Ayala, J.H.; González, V.; Afonso, A.M. Ionic liquids as mobile phase additives in high-performance liquid chromatography with electrochemical detection: application to the determination of heterocyclic aromatic amines in meatbased infant foods. Talanta, 2009, 79(3), 590-597.

[http://dx.doi.org/10.1016/j.talanta.2009.04.032] [PMID: 19576417]

[59] Mazzeo, J. R., D.; Neue, U.; Kele, M.; Plumb, R. S. Advancing LC Performance with Smaller Particles and Higher Pressure Analytical Chemistry, 2005, 77(23), 460A-467.

[http://dx.doi.org/10.1021/ac053516f]

[60] Mohammad Khairul, A.; Rumana, T.; Mohammad Sharif, K.; Jannatul, A.; Abu Tareq Mohammad, A.; Maksuda, K. Chromatographic Assessment of Polyphenolic Profile and Total Phenolic Content and Antioxidant Activity of Common Leafy Vegetables in Bangladesh. Curr. Chromatogr., 2020, 7, 1-11. [http://dx.doi.org/10.2174/2213240607999200421144940]

[61] Mokhtar, S.U.; Chin, S.T.; Vijayaraghavan, R.; MacFarlane, D.R.; Drummer, O.H.; Marriott, P.J. Direct ionic liquid extractant injection for volatile chemical analysis - a gas chromatography sampling technique. Green Chem., 2015, 17(1), 573-581. [http://dx.doi.org/10.1039/C4GC01364F]

[62] Moreda-Piñeiro, J.; Moreda-Piñeiro, A. Chapter Seventeen - Recent Advances in the Combination of Assisted Extraction Techniques.Comprehensive Analytical Chemistry; Ibáñez, E.; Cifuentes, A., Eds.; Elsevier, 2017, Vol. 76, pp. 519-573.

[63] Munir, M.A.; Badri, K.H. The Importance of Derivatizing Reagent in Chromatography Applications for Biogenic Amine Detection in Food and Beverages. J. Anal. Methods Chem., 2020, 2020 ,
5814389 .

[http://dx.doi.org/10.1155/2020/5814389] [PMID: 32377440]

[64] Nagasawa, Y.; Samoto, H.; Ukai, H.; Okamoto, S.; Itoh, K.; Hanada, T.; Kanemaru, A.; Fukui, Y.; Kojima, S.; Moriguchi, J.; Sakuragi, S.; Ohashi, F.; Takada, S.; Kawakami, T.; Ikeda, M. Use of organic solvents in large research institutions in Japan. Environ. Health Prev. Med., 2013, 18(5), 341-348.

[http://dx.doi.org/10.1007/s12199-012-0327-1]

[PMID: 23404090

[65] Oberlies, N.H.; Knowles, S.L.; Amrine, C.S.M.; Kao, D.; Kertesz, V.; Raja, H.A. Droplet probe: coupling chromatography to the in situ evaluation of the chemistry of nature. Nat. Prod. Rep., 2019, 36(7), 944-959.

[http://dx.doi.org/10.1039/C9NP00019D] [PMID: 31112181]

[66] Pagliano, E. Versatile derivatization for GC-MS and LC-MS: alkylation with trialkyloxonium tetrafluoroborates for inorganic anions, chemical warfare agent degradation products, organic acids, and proteomic analysis. Anal. Bioanal. Chem., 2020, 412(9), 1963-1971.

[http://dx.doi.org/10.1007/s00216-019-02299-8]

[PMID: 31915869]

[67] Pang, K.; Hou, Y.; Wu, W.; Guo, W.; Peng, W.; Marsh, K.N. Efficient separation of phenols from oils via forming deep eutectic solvents. Green Chem., 2012, 14(9), 2398-2401.

[http://dx.doi.org/10.1039/c2gc35400d]

[68] Pedersen-Bjergaard, S.; Rasmussen, K.E. Electrokinetic migration across artificial liquid membranes. New concept for rapid sample preparation of biological fluids. J. Chromatogr. A, 2006, 1109(2), 183-190.

[http://dx.doi.org/10.1016/j.chroma.2006.01.025]

[PMID: 16445928

[69] Pereira, F. P. Miniaturization in Sample Preparation: De Gruyter 2015.

[70] Plaza, M.; Turner, C. Pressurized hot water extraction of bioactives Green Extraction Techniques: Principles, Advances and Applications, 2017, 76, 53e82.

[http://dx.doi.org/10.1016/bs.coac.2016.12.005]

[71] Pojjanapornpun, S.; Nolvachai, Y.; Aryusuk, K.; Kulsing, C.; Krisnangkura, K.; Marriott, P.J. Ionic liquid phases with comprehensive two-dimensional gas chromatography of fatty acid methyl esters. Anal. Bioanal. Chem., 2018, 410(19), 4669-4677.

[http://dx.doi.org/10.1007/s00216-018-0944-7] 29455287]

[72] Qualley, A.; Hughes, G.T.; Rubenstein, M.H. Data quality improvement for field-portable gas chromatography-mass spectrometry through the use of isotopic analogues for in-situ calibration. Environ. Chem., 2020, 17(1), 28-38.

[http://dx.doi.org/10.1071/EN19134]

[73] Rahman, M. Application of Computational Methods in Isolation of Plant Secondary Metabolites.Computational Phytochemistry; Sarker, S.D.; Nahar, L., Eds.; Elsevier, 2018, pp. 107-139. [http://dx.doi.org/10.1016/B978-0-12-812364-5.00004-3]

[74] Ratti, R. Industrial applications of green chemistry: Status, Challenges and Prospects. SN Applied Sciences, 2020, 2(2), 263.

[http://dx.doi.org/10.1007/s42452-020-2019-6]

[75] Rezaee, M.; Yamini, Y.; Shariati, S.; Esrafili, A.; Shamsipur, M. Dispersive liquid-liquid microextraction combined with high-performance liquid chromatography-UV detection as a very simple, rapid and sensitive method for the determination of bisphenol $\mathrm{A}$ in water samples. J. Chromatogr. A, 2009, 1216(9), 1511-1514.

[http://dx.doi.org/10.1016/j.chroma.2008.12.091] [PMID: 19167003]

[76] Roy, D.; Wahab, M.F.; Berger, T.A.; Armstrong, D.W. Ramifications and Insights on the Role of Water in Chiral Sub/Supercritical Fluid Chromatography. Anal. Chem., 2019, 91(22), 14672-14680. [http://dx.doi.org/10.1021/acs.analchem.9b03908] [PMID: 31657544]

[77] Rykowska, I.; Ziemblińska, J.; Nowak, I. Modern approaches in dispersive liquid-liquid microextraction (DLLME) based on ionic liquids: a review. J. Mol. Liq., 2018, 259, 319-339. [http://dx.doi.org/10.1016/j.molliq.2018.03.043]

[78] Sakai, M.; Hayakawa, Y.; Funada, Y.; Ando, T.; Fukusaki, E.; Bamba, T. Development of a practical online supercritical fluid ex- 
traction-supercritical fluid chromatography/mass spectrometry system with an integrated split-flow method. J. Chromatogr. A, 2019, 1592, 161-172.

[http://dx.doi.org/10.1016/j.chroma.2019.01.044] [PMID: $30712818]$

[79] Seeley, J.V.; Seeley, S.K. Multidimensional gas chromatography: fundamental advances and new applications. Anal. Chem., 2013, $85(2), 557-578$

[http://dx.doi.org/10.1021/ac303195u] [PMID: 23137217]

[80] Shaaban, H.; Górecki, T. Current trends in green liquid chromatography for the analysis of pharmaceutically active compounds in the environmental water compartments. Talanta, 2015, 132, 739-752.

[http://dx.doi.org/10.1016/j.talanta.2014.09.050]

[PMID: 25476373]

[81] Shahbaz, K.; Mjalli, F.; Hashim, M.; AlNashef, I. Eutectic solvents for the removal of residual palm oil-based biodiesel catalyst. Separ. Purif. Tech., 2011, 81(2), 216-222.

[http://dx.doi.org/10.1016/j.seppur.2011.07.032]

[82] Sharif, K.; Rahman, M.; Azmir, J.; Mohamed, A.; Jahurul, M.; Sahena, F.; Zaidul, I. Experimental design of supercritical fluid extraction-A review. J. Food Eng., 2014, 124, 105-116.

[http://dx.doi.org/10.1016/j.jfoodeng.2013.10.003]

[83] Sharif, K.; Rahman, M.; Azmir, J.; Shamsudin, S.H.; Uddin, M.; Fahim, T.; Zaidul, I. Ethanol modified supercritical carbon dioxide extraction of antioxidant rich extract from Pereskia bleo. J. Ind. Eng. Chem., 2015, 21, 1314-1322.

[http://dx.doi.org/10.1016/j.jiec.2014.05.047]

[84] Sharif, K.M.; Chin, S-T.; Kulsing, C.; Marriott, P.J. The microfluidic Deans switch: 50 years of progress, innovation and application. Trends Analyt. Chem., 2016, 82, 35-54. [http://dx.doi.org/10.1016/j.trac.2016.05.005]

[85] Sheldon, R.A. Metrics of green chemistry and sustainability: past, present, and future. ACS Sustain. Chem.\& Eng., 2018, 6(1), 32-48. [http://dx.doi.org/10.1021/acssuschemeng.7b03505]

[86] Sivapragasam, M.; Moniruzzaman, M.; Goto, M. An overview on the toxicological properties of ionic liquids toward microorganisms. Biotechnol. J., 2020, 15(4), e1900073. [http://dx.doi.org/10.1002/biot.201900073] [PMID: 31864234]

[87] Smith, E.L.; Abbott, A.P.; Ryder, K.S. Deep eutectic solvents (DESs) and their applications. Chem. Rev., 2014, 114(21), $11060-11082$

[http://dx.doi.org/10.1021/cr300162p] [PMID: 25300631]

[88] Soares da Silva Burato, J.; Vargas Medina, D.A.; de Toffoli, A.L.; Vasconcelos Soares Maciel, E.; Mauro Lanças, F. Recent advances and trends in miniaturized sample preparation techniques. J. Sep. Sci., 2020, 43(1), 202-225.

[http://dx.doi.org/10.1002/jssc.201900776] [PMID: 31692234]

[89] Talebi, M.; Patil, R.A.; Armstrong, D.W. Springer, 2020, pp. Gas Chromatography Columns Using Ionic Liquids as Stationary Phase.Commercial Applications of Ionic Liquids; 131-165. [http://dx.doi.org/10.1007/978-3-030-35245-5_6]

[90] Tan, T.; Zhang, M.; Wan, Y.; Qiu, H. Utilization of deep eutectic solvents as novel mobile phase additives for improving the separation of bioactive quaternary alkaloids. Talanta, 2016, 149, 85-90. [http://dx.doi.org/10.1016/j.talanta.2015.11.041] [PMID 26717817]

[91] Tang, B.; Bi, W.; Zhang, H.; Row, K.H. Deep eutectic solvent-based HS-SME coupled with GC for the analysis of bioactive terpenoids in Chamaecyparis obtusa leaves. Chromatographia, 2014, 77(3-4), 373-377.

[http://dx.doi.org/10.1007/s10337-013-2607-3]

[92] Tang, B.; Row, K.H. Exploration of deep eutectic solvent $\square$ based mesoporous silica spheres as high $\square$ performance size exclusion chromatography packing materials. J. Appl. Polym. Sci., 2015, 132(27)

[http://dx.doi.org/10.1002/app.42203]

[93] Tang, B.; Zhang, H.; Row, K.H. Application of deep eutectic solvents in the extraction and separation of target compounds from various samples. J. Sep. Sci., 2015, 38(6), 1053-1064. [http://dx.doi.org/10.1002/jssc.201401347] [PMID: 25581398]

[94] Taylor, T. The LCGC Blog: Is Hydrogen the Only Viable Gas Chromatography Carrier Gas for the Long-Term? Column, 2019,
15(10), 24-31.

[95] Teo, C.C.; Tan, S.N.; Yong, J.W.H.; Hew, C.S.; Ong, E.S. Validation of green-solvent extraction combined with chromatographic chemical fingerprint to evaluate quality of Stevia rebaudiana Bertoni. J. Sep. Sci., 2009, 32(4), 613-622.

[http://dx.doi.org/10.1002/jssc.200800552] [PMID: 19160370]

[96] Teo, C.C.; Tan, S.N.; Yong, J.W.H.; Hew, C.S.; Ong, E.S. Pressurized hot water extraction (PHWE). J. Chromatogr. A, 2010, 1217(16), 2484-2494.

[http://dx.doi.org/10.1016/j.chroma.2009.12.050]

[PMID: 20060531]

[97] Trujillo-Rodríguez, M.J.; Rocío-Bautista, P.; Pino, V.; Afonso, A.M. Ionic liquids in dispersive liquid-liquid microextraction. Trends Analyt. Chem., 2013, 51, 87-106. [http://dx.doi.org/10.1016/j.trac.2013.06.008]

[98] Tucker, J.L.; Faul, M.M. Industrial research: Drug companies must adopt green chemistry. Nature, 2016, 534(7605), 27-29. [http://dx.doi.org/10.1038/534027a] [PMID: 27251259]

[99] Veleva, V.; Cue, B.W., Jr Benchmarking green chemistry adoption by "big pharma" and generics manufacturers. Benchmarking (Bradf.), 2017.

[http://dx.doi.org/10.1108/BIJ-01-2016-0003]

[100] Waichigo, M.M.; Danielson, N.D. Ethylammonium formate as an organic solvent replacement for ion-pair reversed-phase liquid chromatography. J. Chromatogr. Sci., 2006, 44(10), 607-614.

[http://dx.doi.org/10.1093/chromsci/44.10.607] [PMID: 17254370]

[101] Wang, Q.; Chen, X.; Qiu, B.; Zhou, L.; Zhang, H.; Xie, J.; Luo, Y.; Wang, B. Ionic liquid as a mobile phase additive in high-performance liquid chromatography for the simultaneous determination of eleven fluorescent whitening agents in paper materials. $J$. Sep. Sci., 2016, 39(7), 1242-1248.

[http://dx.doi.org/10.1002/jssc.201501050] [PMID: 26843408]

[102] Widger, P.; Haddad, A.M. Analysis of Gaseous By-Products of $\mathrm{CF}_{3} \mathrm{I}$ and $\mathrm{CF}_{3} \mathrm{I}_{-}-\mathrm{CO}_{2}$ after High Voltage Arcing Using a GCMS. Molecules, 2019, 24(8), 1599.https://www.mdpi.com/1420-3049/24/8/1599

[http://dx.doi.org/10.3390/molecules24081599] 31018513]

[103] Xu, L.; Basheer, C.; Lee, H.K. Developments in single-drop microextraction. J. Chromatogr. A, 2007, 1152(1-2), 184-192. [http://dx.doi.org/10.1016/j.chroma.2006.10.073] 17097670]

[104] Yabré, M.; Ferey, L.; Somé, I.T.; Gaudin, K. Greening Reversed-Phase Liquid Chromatography Methods Using Alternative Solvents for Pharmaceutical Analysis. Molecules, 2018, 23(5), 1065.https://www.mdpi.com/1420-3049/23/5/1065 [http://dx.doi.org/10.3390/molecules23051065] 29724076]

[105] Yamini, Y.; Rezazadeh, M.; Seidi, S. Liquid-phase microextraction-The different principles and configurations. Trends Analyt. Chem., 2019, 112, 264-272.

[http://dx.doi.org/10.1016/j.trac.2018.06.010]

[106] Yang, D.; Hou, M.; Ning, H.; Zhang, J.; Ma, J.; Yang, G.; Han, B. Efficient SO 2 absorption by renewable choline chloride-glycerol deep eutectic solvents. Green Chem., 2013, 15(8), 2261-2265.

[http://dx.doi.org/10.1039/c3gc40815a]

[107] Yilmaz, E.; Soylak, M. Ultrasound assisted-deep eutectic solvent extraction of iron from sheep, bovine and chicken liver samples. Talanta, 2015, 136, 170-173.

[http://dx.doi.org/10.1016/j.talanta.2014.12.034]

[PMID: 25702999]

[108] Zaibunnisa, A.H.; Norashikin, S.; Mamot, S.; Osman, H. An experimental design approach for the extraction of volatile compounds from turmeric leaves (Curcuma domestica) using pressurised liquid extraction (PLE). Lebensm. Wiss. Technol., 2009, 42(1), 233-238

[http://dx.doi.org/10.1016/j.lwt.2008.03.015]

[109] Zgoła-Grześkowiak, A.; Kaczorek, E. Isolation, preconcentration and determination of rhamnolipids in aqueous samples by dispersive liquid-liquid microextraction and liquid chromatography with tandem mass spectrometry. Talanta, 2011, 83(3), 744-750. [http://dx.doi.org/10.1016/j.talanta.2010.10.037]

[PMID: 
21147315]

[110] Zhang, Q.; De Oliveira Vigier, K.; Royer, S.; Jérôme, F. Deep eutectic solvents: syntheses, properties and applications. Chem. Soc. Rev., 2012, 41(21), 7108-7146.

[http://dx.doi.org/10.1039/c2cs35178a] [PMID: 22806597]

[111] Zhao, X.; Cai, P.; Sun, C.; Pan, Y. Application of ionic liquids in separation and analysis of carbohydrates: State of the art and fu- ture trends. Trends Analyt. Chem., 2019, 111, 148-162.

[http://dx.doi.org/10.1016/j.trac.2018.12.008]

[112] Zheng, J.; Row, K.H. Effects of ionic liquid on the separation of 2-chlorophenol and 2,4,6-trichlorophenol in RP-HPLC. J. Chromatogr. Sci., 2009, 47(5), 392-395.

[http://dx.doi.org/10.1093/chromsci/47.5.392] [PMID: 19476708] 